\title{
El personaje del emperador romano en el Auto de la destrucción de Jerusalén
}

\section{The Character of the Roman Emperor inn the Auto de la destruceión de Jeruisalén}

\section{Said Ilich Trujillo Valverde}

Pontificia Universidad Católica del Perú, Lima, Perú

Contacto: said.trujillo@pucp.edu.pe

https://orcid.org/0000-0003-3793-3632

\section{RESUMEN}

Este artículo analiza la versión náhuatl del Auto de la destrucción de Jerusalén, pieza teatral del período de la evangelización en el virreinato de la Nueva España, a partir de la comparación con dos obras cercanas en el tiempo: su contraparte en castellano, presente en el Códice de autos viejos, y La destruicion de Jerusalem -también conocida como la Historia del noble Vespasiano-, texto en prosa que desarrolla el mismo motivo que las otras dos obras mencionadas. Consideramos que es posible observar que la obra del teatro evangelizador mexicano, sin alejarse en demasía de las acciones presentadas en las otras piezas, transforma una obra de raíces antisemitas en una validación de la conquista americana. El foco de atención de la investigación estará puesto en la figura del emperador Vespasiano que funciona, proponemos, como un análogo del emperador Carlos $\vee$ y no como una alegoría de los caciques nativos, una interpretación presentada por la crítica anterior. La analogía entre Vespasiano y Carlos $V$ se construye en el texto náhuatl a partir del relativo encubrimiento de la condición pagana de Vespasiano -característica relievada en las dos obras castellanas- y del énfasis que el auto novohispano les pone a los derechos territoriales del emperador.

Palabras clave: Teatro colonial; Teatro evangelizador; Emperador romano; Carlos V; Auto de la destrucción de Jerusalén.

\section{ABSTRACT}

This article analyzes the Nahuatl version of the Auto de la destrucción de Jerusalén, a theater piece belonging to the period of the evangelization in the Viceroyalty of New Spain, based on the comparison with two works that are close in time: its counterpart in Spanish, present in the Códice de autos viejos, and La destruicion de Jerusalem, a prose text that develops the same motif as the other two works mentioned. We consider that it is possible to observe that the work of the Mexican evangelizing theater, without straying too far from the actions presented in the other pieces, transforms a work with anti-Semitic roots into a validation of the American conquest. The focus of the research will be on the figure of the Emperor Vespasian who functions, we propose, as an analog of the Emperor Charles $V$ and not as an allegory of the native chiefs, an interpretation presented by the previous critic. The analogy between Vespasiano and Carlos $V$ is built in the Nahuatl text from the relative cover-up of Vespasian's pagan condition -a characteristic highlighted in the two Castilian worksand from the emphasis that the New Spanish auto places on the territorial rights of the emperor.

Keywords: Colonial theater; Evangelizing theater; Roman Emperor; Charles V; Auto de la destrucción de Jerusalén. 


\section{Introducción: el corpus}

La versión náhuatl ${ }^{1}$ del Auto de la destrucción de Ferusalén que conocemos es, según Fernando Horcasitas (1974), un manuscrito del siglo XVIII sobre el que puede especularse que es una copia tardía de un texto que podría fecharse en la época de la evangelización. Beatriz Aracil Varón considera que el autor de esta pieza en lengua nativa "debió ser un franciscano o un indio educado por miembros de dicha orden que, todavía en el siglo XVI, trasladó a esta lengua un texto anterior" (1999, p. 31). A su vez, la misma Aracil Varón especula con la posibilidad de que tanto esta versión náhuatl como la versión española tengan su origen común en la Historia del noble Vespasiano².

De idéntico título es una de las piezas que figuran en el Códice de autos viejos ${ }^{3}$. El Códice es una colección de 96 obras predominantemente religiosas, pues solo una es de tema profano. Mercedes de los Reyes Peña (1999) considera que las obras del Códice fueron de forma plausible "un repertorio dramático para la festividad del Corpus" (p. 18) y que deben datarse entre 1550 y 1575 . La misma estudiosa señala que pese a la unidad del tema religioso, es posible clasificar en grupos temáticos las obras del Códice: "Historiales (bíblicos, hagiográficos, mariológicos e histórico-legendarios), alegóricos y bíblico-alegóricos" (p. 23). El Auto de la destrucción de Jerusalén del Códice y el auto americano no se alejan, esencialmente, en cuanto al argumento dramático: ambas presentan la historia de Vespasiano, un emperador aquejado de lepra que, al ser curado por la intervención de una reliquia, tomará venganza contra Pilatos, quien usurpó la soberanía sobre Jerusalén y, además, fue el asesino de Cristo.

Ambas versiones dramáticas derivarían de una fuente común: de la Historia del noble Vespasiano ${ }^{5}$. Esta Historia se formó a partir de versiones francesas de la leyenda medieval de Vespasiano y la destrucción de Jerusalén. Manuel Cacho Blecua (2016) ha identificado tres ejemplares que recogen la Historia: uno sevillano, el de Pedro Brun de 1499, de 36 páginas y adornado con 15 xilografias; el de Toledo, Juan Vázquez (1491-1494); y el de Lisboa, Valentino de Moravia, 1496, adornado con 27 grabados. Lo importante de estas ediciones, aparte de formalizar la Historia, radica en su relativo "lujo", lo que da cuenta del éxito de esta historia. Parece que el tema tuvo un éxito bastante grande, como apunta el mismo Cacho Blecua:
"El suceso [la destrucción de Jerusalén] fue profusamente recogido, y en muchas ocasiones ilustrado, en muy diversos textos y géneros: libros litúrgicos, exegéticos, de horas, biblias, sermones, literatura religiosa canónica, hagiografía, historiografía, especialmente la relacionada con Josefo, etc.", de ahí que hayan surgido estas ediciones que recogían la historia, además de versiones en la literatura de cordel. Su vínculo con la conquista mexicana ya ha sido desarrollado por Enrique Flores (2003), quien considera que este libro debió de ser conocido por Bernal Díaz del Castillo y hasta por el mismo Cortés.

\section{El tema}

María Rosa Lida de Malkiel (1973) ubica el origen de las elaboraciones sobre la destrucción de Jerusalén en el historiador judío Flavio Josefo. Lida de Malkiel apunta que "[De bello Iudaico] ha tenido una insospechable carrera como argumento teológico que, a su vez, ha refluido sobre la concepción de los hechos narrados" (p. 15). La obra de Josefo sería la principal responsable de que la destrucción de la Ciudad Santa por Tito haya tenido una pervivencia e impacto mayores en la mentalidad europea que la más decisiva rebelión judía aplacada en tiempos del emperador Adriano. Para la crítica nacida en Argentina, el tema del castigo del pueblo judío será analizado en la literatura patrística - destaca la opinión de san Agustín, quien en La ciudad de Dios había considerado que Dios no había liquidado a los judíos para que sean la muestra del triunfo del evangelio, o sea, en la interpretación de Lida de Malkiel, "la dispersión [de los judíos] como testimonio universal, correlativo de la universalidad de la Iglesia" (1973, p. 24) - y en autores como santo Tomás, quien opinaba que el castigo de los judíos era correlativo a la magnitud de su culpa. Las elaboraciones ficcionales iniciarían cuando "[f] rente a la consideración abstracta de un San Agustín o un Santo Tomás, el populacho medieval se apodera de aquel hecho y lo reelabora dentro de las normas de su mentalidad" (Lida de Malkiel, 1973, p. 26).

Una buena genealogía del tema la da el ya citado Juan Manuel Cacho Blecua quien, situando también el inicio en la versión de Flavio Josefo - que pasará a la Edad Media en una refundición llamada $D e$ excidio Hierosolymitano muy famosa para el siglo IX-, ubica hacia fines del siglo XII o inicios del siglo XIII 
la fijación de los temas principales que serán tratados posteriormente en el cantar de gesta Venjance Notre Seigneur, una épica religiosa que añadía historias sacadas de tres evangelios apócrifos: la Cura sanitatis Tiberii, la Vindicta salvatoris ${ }^{6}$ y la Mors Pilati. Las prosificaciones del Venjance Notre Seigneur son las que llegaron a la Península Ibérica y las que dieron origen a la Historia del noble Vespasiano. Con todo, y todavía siguiendo a Cacho Blecua, es necesario señalar que la leyenda de la destrucción de Jerusalén circuló en distintas versiones entre los siglos XV y XVI, no solo bajo el ropaje de la Historia del noble Vespasiano. Sin embargo, que esta haya generado dos obras teatrales en tiempos similares, pero en contextos tan disímiles como el español y el americano, es significativo. Por otro lado, como especula David Hook (2018), la difusión de la leyenda de la destrucción de Jerusalén pudo haber sido tal que para 1583 habría estado circulando en el otro virreinato, el de Perú.

\section{El Auto de la destrucción de Jerusalén y la evangelización}

La idea del teatro como instrumento para la inicial evangelización de la Nueva España fue enarbolada en primera instancia por la orden franciscana. El período de mayor auge de este tipo de actividad teatral puede detectarse en las décadas de 1530 y 1540, las inmediatamente posteriores a la llegada de los franciscanos $^{7}$. Podría decirse que este teatro respondía a una triple función: "sustituir las fiestas paganas, facilitar la enseñanza de la doctrina cristiana a las masas indígenas y hacer esa enseñanza más interesante a los ojos de los indios" (Aracil Varón, 2016, p. 40). Para mejor responder a tales funciones, este teatro se hacía en la lengua nativa y se empleaba a los naturales en su ejecución ${ }^{8}$.

En este contexto corresponde ubicar la versión náhuatl del Auto de la destrucción de Jerusalén. ¿Por qué una obra lejana en sus contenidos a los referentes locales podría ser útil en el afán de aculturar a las poblaciones nativas? La Historia del noble Vespasiano, el presumible origen tanto de esta pieza como de la versión castellana, desarrolla como objetivos evidentes realizar un discurso antisemita, exaltar la religión cristiana, dar nociones generales del credo cristiano y valorar el rol de las reliquias en la curación de enfermedades ${ }^{9}$. Ciertamente, los episodios catequísticos y la reivindicación del valor de las reliquias ${ }^{10}$ ya justificaban una representación para un público al que había que evangelizar. En adición a lo anterior, para Aracil Varón (1999) la elección de este tema como opción de texto evangelizador tenía además "la clara intención de los frailes de apoyar el poder español en América" (p. 30). Consideramos que lo anterior se explica mejor si se entiende a Vespasiano como un reflejo de Carlos V, ampliando una interpretación ya esbozada por Carlos Solórzano (1992) ${ }^{11}$.

En las muy famosas cartas de relación de Hernán Cortés (1866), cuando este se dirige a Carlos V, la fórmula empleada será "S. C. Ces. M.": Sacra católica cesárea majestad. El tratamiento protocolario que distingue a este monarca Habsburgo es la inclusión del adjetivo "cesárea", en consonancia con su condición de emperador del Sacro Imperio Romano Germánico (SIRG). Y si bien puede cuestionarse la legitimidad del SIRG en lo que respecta a la sucesión del Imperio romano, lo cierto es que con Carlos V por fin se había logrado la vieja obsesión frustrada de Alfonso X, el Sabio, quien siglos antes había bregado para ser elegido emperador. Sea como fuere, a nivel ideológico y propagandístico el cargo de emperador aún tenía un valor superlativo. Si se piensa en el contexto de la conquista de México, la cuestión es harto más significativa:

[L]a tradición europea contemporánea a la Conquista concebía la existencia de una sociedad política universal, la Respublica Christana; ésta asumía la doble forma de una Iglesia y de un Imperio, idea nutrida por la tradición universalista de Roma, que reflejaba la aspiración a la unidad del género humano. En tiempos de Cortés y desde el momento en que fue elegido el [sic] trono del Sacro Imperio en 1519, Carlos V se convirtió en la encarnación de esta doble tradición. (Weckmann, 1994, p. 319)

Una vinculación directa entre la figura de Carlos V y las representaciones teatrales puede verse en la Historia de los indios de la Nueva España de fray Toribio de Motolinía (2014 [1541]) en la que el personaje del emperador protagoniza una conquista de Jerusalén ayudado por el papa y un variado ejército. En el llamado Auto de la conquista de Jerusalén ${ }^{12}$, descrito por Motolinía, se emplea la fórmula protocolar ya señalada, como da cuenta el inicio de la carta 
de don Antonio de Mendoza: "Sacra, Cesárea, Católica Majestad: Emperador Semper Augusto" (p. 97). Destacable también es que además del propio Carlos $\mathrm{V}$ también aparece el papa en intercambios epistolares, y como personaje clave para la conquista de Jerusalén. Como ha destacado Aracil Varón (2000 [1994]), algo particular que presenta esta obra de la que da cuenta Motolinía es que la toma de la Ciudad Santa tiene como consecuencia una conversión en masa de los moros que habitaban Jerusalén, lo cual es interpretado por la investigadora como resultado de ser una obra pensada para la realidad americana: "la posibilidad de conversión de los moros, incomprensible en la mentalidad tradicional de cruzada, es una plasmación clara de la realidad mexicana, de la conversión de los indios" (s/p). Por otro lado, ya pensando en la obra objeto de este trabajo, es significativo que en el Auto de la conquista de Ferusalén dos roles protagónicos estén reservados para el papa y el emperador, una dinámica que se repite en el Auto de la destrucción de Jerusalén, obra en la que estos papeles son asumidos por Clemente y Vespasiano.

Ciertamente, la repetición de cargos o los meros significantes "emperador" o "papa" son insuficientes para afirmar una correlación directa; no obstante, teniendo en cuenta el valor simbólico de la palabra "emperador" y que directamente la figura de Carlos V había aparecido ya en una representación dramática tomando Jerusalén, nos parece plausible pensar que el Vespasiano del Auto de la destrucción de Jerusalén náhuatl podría interpretarse como un análogo del emperador de la casa Habsburgo.

Un buen punto de partida puede ser la revisión comparativa de los temas tratados por las tres versiones de la historia de Vespasiano y la prioridad con la que aparecen. Si se cotejan los inicios del auto en lengua nativa con la versión en castellano y con la Historia del noble Vespasiano, es posible ya encontrar diferencias considerables. El inicio del auto náhuatl tiene a Vespasiano lamentándose de la falta de respuesta de Pilatos, quien se niega a cumplir sus deberes para con él: "¡Hace tres años que desde aquí, desde Roma, le escribí a Pilatos!" (Anónimo, 1974, p. 465). Luego de este breve diálogo, la acción pasa a la corte de Pilatos y no retornará a Roma hasta lo que el editor ha llamado "Cuadro III".
Para el caso del auto en castellano (Anónimo, 2003), la parte inicial también tiene al emperador romano, pero con la diferencia esencial de que este se lamenta a sus dioses por el mal que sufre:

Inclinad vuestros oídos, ¡oh mis dioses inmortales!, a mis ansias y gemidos, y a mis penas y alaridos y dolores desiguales.

Pues que me constituistes en tan suprema altitud vos, mis dioses, me subistes, ¿por qué agora me abatistes con falta de mi salud? Todo cuanto yo he podido en toda mi monarquía otra ley no he consentido, sino adorado y servido y honrado la idolatría. (vv. 16-30)

Este inicio y presentación de Vespasiano está más cercano al de la Historia del noble Vespasiano, pues en esta obra lo primero que sabemos del emperador es que: "Este emperador Vespasiano adoraua los ydolos, e auia grandes riquezas, e deleytauase en los vicios carnales deste mundo" (Anónimo, 1908, p. 379). Si bien es cierto que en el auto castellano se elide la mención a los "vicios carnales", lo cual ya da cuenta de una diferencia respecto de las versiones anteriores de la leyenda ${ }^{13}$, la condición de gentilidad del emperador es remarcada desde el inicio en estas dos versiones en castellano. En la pieza náhuatl se sabrá de forma explícita que Vespasiano no es cristiano solo cuando Clemente le dé el discurso catequístico y le presente a Verónica, quien lo curará con su reliquia.

El contraste entre las versiones en lengua romance y la obra teatral en lengua nativa es significativo si se piensa en interpretaciones anteriores sobre la figura de Vespasiano. Por ejemplo, la ya citada Beatriz Aracil Varón, cuyos trabajos son ineludibles y han contribuido sobremanera al estudio del tema, mencionaba que "la obra daba un argumento de autoridad a la conversión de los propios naturales al tiempo que permitía una identificación entre los caciques y principales indígenas y el recién convertido Vespasiano" (1999, p. 32). No obstante, si lo que se buscaba presentar a los naturales era la historia de un pagano que se convierte, ¿no habría tenido más sentido insistir en la adoración a los ído- 
los con la que se inicia la Historia del noble Vespasiano o el auto castellano? Recordemos que en la obra náhuatl el primer diálogo de Vespasiano, que luego cederá protagonismo a Pilatos, no da cuenta ni de su enfermedad ni de su desagrado con sus dioses por no curarlo; es un reclamo a la insumisión de un gobernador rebelde.

La cuestión política está, pues, más marcada en el inicio del texto náhuatl. No parece funcionar del todo satisfactoriamente la idea de un Vespasiano construido para ser un reflejo de los caciques en vista de que atributos que sí se desarrollan en las versiones en castellano están ausentes en la pieza americana. De ahí que parezca pertinente desarrollar la interpretación de Luis Carlos Salazar Quintana:

Si hacemos una lectura de carácter ideológico la
obra [la versión náhuatl del Auto de destrucción de
Jerusalén] lleva al espectador indígena a entender
que los reyes aztecas debían ofrendar a los con-
quistadores con sus riquezas y rendirles tributo y
obediencia al monarca español del mismo modo
que los gobernadores romanos lo hacían con su
emperador. (1999, p. 150)

Consideramos que no se está desarrollando solamente la idea de que Pilatos es castigado por faltar a sus deberes para con el emperador en analogía a los deberes que ahora le deben los jefes del territorio mexicano a la corona española, sino que directamente se está estableciendo que el emperador romano, sea Vespasiano o Carlos V, tiene un dominio territorial universal incontrovertible que alcanza también las tierras americanas.

Todo ello queda reforzado por el hecho de que el primer diálogo de Arquelao, el consejero de Pilatos, en la obra náhuatl ya trae la idea de que "tal como nosotros cuidamos a nuestra ciudad de Jerusalén, así cuida él [Vespasiano] su ciudad de Roma" (Anónimo, 1974, p. 465). El "Archelao" del auto castellano dice unas líneas parecidas: "Decilde (sic) que en Roma estén / en guarda de sus contrarios, / que ansí haréis vos también / guardando a Jerusalén / de los vuestros adversarios" (vv. 271-275). En la Historia del noble Vespasiano, el diálogo de Barrabás - que hace las veces de Arquelao en ese pasaje específico - se desarrolla de manera algo diferente: "mas le cunple a el que sea señor de Roma e de Lonbardia" (Anónimo, 1908, p. 382), aunque con todo, desarrolla la misma idea de que Vespasiano se quede en Roma y Pilatos se haga cargo de Jerusalén.

Lo que destaca de la obra americana en relación con sus pares europeos es que el consejo de Arquelao ocurre muy al inicio, es el tercer diálogo en toda la obra, mientras que en el auto castellano se encuentra con la obra ya relativamente avanzada ${ }^{14} \mathrm{y}$ en la Historia del noble Vespasiano Barrabás hablará en el capítulo VII. ¿Qué es lo que implica el consejo de Arquelao/Archelao/Barrabás?, directamente, el desacato a la autoridad imperial. El dominio universal del emperador se ve amenazado en tanto un súbdito busca hacerse con un poder que no le pertenece. Que este conflicto se halle tan al inicio en el auto en náhuatl permite especular con la idea de que se buscaba centrar el interés del público nativo en el desacato de Pilatos antes que en la conversión de Vespasiano.

Ya es posible ver una constante en la obra en náhuatl que la distingue de las otras dos sin transformar radicalmente los hechos que se cuentan: la obra americana pone énfasis en el conflicto político desde un momento bastante prematuro. Si el primer interés que se está construyendo se vincula con el desafiado poder de Vespasiano y se está construyendo la justificación para su reacción en contra del rebelde Pilatos, es muy difícil pensar en este personaje como una figura que recuerde a los caciques que se someterán a la corona española. El justo derecho del emperador sobre los territorios de Pilatos sí parece ser un escenario extrapolable a la conquista americana, lo cual merece un análisis más detallado.

\section{El requerimiento de Vespasiano}

El requerimiento fue un documento jurídico redactado en 1513 por Martín Fernández de Enciso y el doctor Palacios Rubio y que, como apunta Roberto Marín Guzmán (2006), estaba "plagado de términos legales, de citas bíblicas y de mención a las Bulas de Donación del papa Alejandro VI” (p. 540). Básicamente era una justificación legal de la conquista: si la población nativa que escuchaba el requerimiento no se sometía, los españoles estaban jurídicamente justificados para ejecutar una "guerra justa". Como ha señalado Paja Faudree (2015), el requerimiento "descends from medieval legal traditions circulating throughout Christian Europe concerning just war and the rights of non-Christians" (p. 456). 
Para los fines de este trabajo es relevante recordar el requerimiento y, en específico, una de las ideas que se esgrimían en ese documento jurídico: el dominio del mundo entregado a la corona española por parte del papa, sucesor de san Pedro. El requerimiento de 1513 indicaba:

Uno de los Pontífices pasados que en lugar de éste [san Pedro] sucedió en aquella dignidad y silla que he dicho, como señor del mundo hizo donación de estas islas y tierra firme del mar Océano a los dichos Rey y Reina y sus sucesores en estos Reinos. (López de Palacios, 2016 [1513], $\mathrm{s} / \mathrm{p})$

En las etapas más avanzadas de la conquista de México, con Carlos V ya firmemente en el trono del SIRG, la fórmula debió de cambiar y ser más parecida a la que aparece en el discurso que da el padre Valverde a Atahualpa, según la versión del Inca Garcilaso de la Vega:

Por tanto el Papa Romano Pontífice, que hoy vive en la tierra, entendiendo que todas las gentes y naciones de estos reinos, dejando a un Dios verdadero, hacedor de todos ellos, adoran torpísimamente los ídolos y semejanzas del demonio, queriendo traerlas al verdadero conocimiento de Dios, concedió la conquista de estas partes a Carlos Quinto, Emperador de los Romanos, Rey poderosísimo de las Españas, y monarca de toda la tierra. (2009 [1617], p. 73)

De cierta forma el título imperial de Carlos $\mathrm{V}$ refuerza, para fines propagandísticos, el contenido del requerimiento. Ahora el monarca no solo es el receptor de una donación del papa, sino que es el monarca universal. Seguramente para los naturales esto debió de ser algo relativamente insustancial, pero para los europeos era un asunto de suma importancia.

¿Cómo se conecta lo anterior con las obras materia de este trabajo? Ya se ha mencionado que, en el Auto de la destrucción de ferusalén usado para la evangelización, el tema político tiene un lugar preeminente. Teniendo eso en cuenta, no es descabellado pensar el episodio del enfrentamiento verbal entre Pilatos y Vespasiano, y la posterior destrucción de la ciudad, como imágenes del requerimiento y de las represalias de no someterse al requerimiento.
Señala Robert Ricard (2017) que en la elección de temas para la representación del teatro evangelizador se tenía en cuenta la historia reciente, y pone de ejemplo la cuestión de la antropofagia para el caso del Auto de la destrucción de Ferusalén:

[...] el episodio de las madres judías que, acosadas por el hambre, matan y devoran a sus hijuelos, no aparece en la versión mexicana: peligroso, a la verdad, hubiera sido ponerlo en escena ante espectadores entre quienes los sacrificios humanos y la antropofagia ritual eran demasiado recientes. (p. 258)

Bajo ese prisma de ver y concebir el teatro en este contexto como capaz de generar poderosas figuras analógicas - lo que se confirma con la necesidad de censurar los temas polémicos que el auditorio potencial pudiera reconocer-, considerar el encuentro entre el emperador y el gobernador como un posible eco del requerimiento parece plausible. En la obra náhuatl Vespasiano le espeta a Pilatos:

¡Ah, conque tú eres el que dejé como guardián de mi casa en la ciudad de Jerusalén! [...] Abre la puerta de la muralla en seguida. Entrégame la ciudad con todos sus tesoros. Si no haces esto pronto mi corazón hará lo que desea. (Anónimo, 1974, p. 473)

El auto castellano presenta un matiz en la solicitud de Vespasiano, puesto que en esta obra el emperador le pregunta a Pilatos “ ¿Eres tú el gobernador / aquel que su majestad / de aquel gran emperador, / César, nuestro antecesor, / encomendó esta ciudad?" (Anónimo, 2003, vv. 406-410) lo cual se parece mucho más a lo que presenta la Historia del noble Vespasiano, obra en la que el emperador le espeta a Pilatos "El noble padre mío te encomendó esta cibdad por / que la guardasses e la rigesses por el, e quiso que fuesses adelantado e gouernador por el de toda esta tierra" (Anónimo, 1908, pp. 387-388). Las dos obras castellanas coinciden en que Pilatos fue designado por un predecesor de Vespasiano, mientras que la obra en náhuatl destaca que fue el mismo Vespasiano quien encargó Jerusalén a Pilatos. Otra vez la obra americana se distingue de sus pares europeos: no busca complicar a su potencial auditorio con genealogías, sino que presenta al emperador como dueño de todos los territorios y que dispone de ellos como mejor le parece. 
Si bien es cierto que no puede haber una analogía directa y precisa con el requerimiento, pues Vespasiano va a reprimir un levantamiento, no a ejecutar su derecho sobre un territorio recién descubierto, la idea de que el emperador es dueño de todos los dominios y que la no rendición implica la destrucción inmisericorde, sí se pueden vincular directamente con aquella práctica jurídica. En todo caso, tanto Vespasiano como Carlos V le deben su poder terrenal al poder divino: sin la conversión, Vespasiano no se habría curado de la lepra; los derechos sobre las tierras americanas le vienen a Carlos V por mano del papa.

$0<$. La falta de piedad mostrada por Vespasiano, que se lee en los textos españoles directamente como parte del mensaje antisemita ${ }^{15}$ de estas obras, en el contexto americano de recepción puede interpretarse como una consecuencia lógica de la desobediencia al emperador. Jerusalén - como los territorios americanos - le pertenece al emperador, como da cuenta el requerimiento y como el auto da a entender: la usurpación de su legítimo derecho, que le viene dado por el santo padre, heredero de san Pedro, valida el uso de la violencia para la restauración del equilibrio roto.

\section{Vespasiano como emperador cristiano}

Si bien a lo largo de este trabajo hemos destacado el valor simbólico del significante "emperador", no hemos señalado que era particularmente relevante para el caso de Carlos V al ser este un soberano de una casa extranjera. Como apunta Henry Kamen (2007):

Una buena parte de la élite de Castilla mostró su rechazo hacia la dinastía extranjera de los Austrias [...]. Sin embargo, la elección de Carlos como emperador del Sacro Imperio Romano en 1520 prometió a los españoles la identificación con un destino nuevo y más estimulante. El nuevo emperador pasó la mayor parte de su vida activa fuera de la Península, pero se apresuró a mostrar el profundo aprecio que sentía por su herencia española, que pronto comenzó a contribuir a sus gastos militares y le convenció de su capacidad para oponerse a las herejías que se difundían por Alemania. (p. 157)

La posición de Carlos V en el trono español no era del todo sólida - es de recordar la guerra de las Comunidades de Castilla de 1520 a 1522, que in- cluso tuvo cierto apoyo de algunos sectores castellanos acomodados-, por lo que el monarca requería de estabilizadores para mantenerse en el poder. Ser emperador y defender la fe católica fueron dos de las banderas esgrimidas para legitimar al nieto de los Reyes Católicos. De ahí que la idea de un emperador cruzado fuera tan relevante.

Ya hemos desarrollado la idea de que el auto náhuatl elide la condición pagana de Vespasiano, a diferencia de las obras castellanas que sí la destacan. Otra diferencia significativa, y vinculada a la anterior, puede verse en relación con el juicio de Pilatos, donde la figura de Vespasiano como un cristiano militante queda relevada. Una vez vencido el gobernador rebelde, este debe comparecer ante el emperador, quien le reiterará por qué no puede haber perdón ni indulto alguno para él; termina siendo así un personaje diabolizado, en el sentido propio del término. Los tres textos estudiados coinciden en presentar los mismos cargos contra Pilatos: primero, que fue el asesino de Jesús; segundo, que se rebeló contra el poder imperial; y, tercero, que le hizo guerra a su legítimo señor. La diferencia está en el desarrollo de estas ideas. En el caso del auto castellano no hay mayor desarrollo de las causas de la condena de Pilatos, para el primero de los cargos, y Vespasiano dirá expeditivamente: "que por tomar amicicia / con el que negaste tú / sentenciaste por malicia, / contra razón y justicia, / al gran profeta Jesú" (Anónimo, 2003, vv. 626-630) su condena es justa. Destaca, en cambio, el desarrollo que hace el auto náhuatl del primer argumento para condenar a Pilatos:

Lo primero es que por maliciosa orden tuya mataron aquí en la cruz al Santo Profeta que se llamaba Jesús Nazareno. Pues bien te diste cuenta ya que reconocieron y confesaron que lo habían calumniado porque era de vida santa. Y ahora nos damos cuenta, por ser vosotros, que no le quisisteis orar; que no le fuisteis agradecidos. Porque si os enfermabais, él os curaba. Cuando moríais, os resucitaba. Por eso escucha: por su muerte os vengo a castigar. (Anónimo, 1974, p. 487)

Es notable la diferencia en la profundidad y en la calidad de la exposición de este primer argumento entre el Vespasiano del auto castellano con el de la obra americana. Mientras el primero solamen- 
te menciona que Jesús fue injustamente condenado a muerte por Pilatos, en la obra náhuatl Vespasiano no solamente dará cuenta de la razón - la injusta muerte de Jesús-, sino que mostrará sus conocimientos acerca del profeta. Es significativo que en el discurso de Vespasiano se reorganicen elementos que antes habían sido puestos de relieve por otros personajes de la pieza castellana.

Vespasiano no solamente está ejecutando un acto de justicia: el emperador sabe lo que hizo Cristo, y de ahí que sea aún más injustificable su muerte. En este punto de la obra, Vespasiano es un ferviente católico que en ejercicio de su majestad imperial está resarciendo el deicidio. La acción del emperador es una de guerra santa: no es cualquier gobernante temporal, es el monarca de un imperio universal con una misión religiosa. Carlos V, al luchar contra los protestantes en Europa y contra la idolatría americana, solo está continuando en la historia real la labor que ya está realizando Vespasiano en la legendaria historia dramatizada.

\section{Conclusiones}

De la comparación entre tres obras que tratan esencialmente un mismo tema es posible determinar la importancia de los actos perlocutivos que se buscan lograr a través de estos tres productos literarios. Así pues, si bien el Auto de la destrucción de Ferusalén náhuatl respeta lo sustancial de la leyenda de Vespasiano y la destrucción de la ciudad santa, es posible detectar contrastes importantes entre el texto americano y las producciones europeas, contrastes que se explicarían en una obra con miras a un público nativo que va a ser evangelizado.

Que la condición pagana de Vespasiano no sea tan relevante en la pieza náhuatl y que, más bien, la cuestión de la rebeldía de Pilatos sea prioritaria, da cuenta de la intención de construir un personaje de emperador más lejano de los caciques indígenas y más cercano a una figura de autoridad que puede equipararse a la de Carlos V. El Habsburgo y Vespasiano no solamente comparten el cargo y la dignidad imperial, sino que pueden verse como análogos en tanto el también rey de España se caracterizó por su lucha contra la heterodoxia religiosa y el antiguo emperador castiga a los primeros enemigos del cristianismo.

Por otro lado, si el requerimiento daba cuenta de la legalidad de la posesión por parte del emperador de las tierras americanas, el auto desarrolla la idea de que el emperador tiene derechos territoriales absolutos y que rebelarse contra esa verdad solo tiene como consecuencia la justa guerra. En suma, tanto el Vespasiano del auto náhuatl como el Carlos V son monarcas universales y a su vez campeones de la cristiandad

\section{Notas}

1 Si bien el texto fue escrito en náhuatl, se trabajará con la traducción proporcionada por Fernando Horcasitas en El teatro náhuatl. Épocas novohispana y moderna. Primera parte, editada en 1974 por el Instituto de Investigaciones Históricas de la Universidad Nacional Autónoma de México.

2 El aserto de Aracil Varón se ubica en la nota 10 de la página 34 de su referido estudio y parte de ideas de María Rosa Lida de Malkiel (1973). Estamos de acuerdo con la afirmación de Aracil Varón; no obstante, en aras del rigor académico, es preciso anotar que, si bien los hechos contados en las tres obras son esencialmente los mismos, la obra en náhuatl presenta una discrepancia significativa en relación con sus pares europeos. En el auto americano, luego de ser derrotado, Pilatos es reclamado por unos personajes presentados como "vienenses" que se llevan al gobernador a Viena. En el auto castellano no se desarrolla el destino posterior de Pilatos y en la Historia del noble Vespasiano se desarrolla la lenta muerte de Pilatos, quien es torturado en la ciudad de Albaña y muere sin arrepentirse de sus acciones. La presencia de los vienenses se corresponde con una leyenda medieval del siglo XIII que ubica el lugar final de Pilatos en Viena, una ciudad en Francia. Lo más posible es que se haya empleado una fuente aparte de la Historia del noble Vespasiano para la construcción del auto náhuatl o que se hayan refundido fuentes distintas. Por otro lado, debido al tema que desarrolla este trabajo, pensar en Viena, no como la ciudad francesa, sino como la urbe austriaca y una alusión al país de origen de 
la dinastía Habsburgo era tentador; sin embargo, por ser esta idea extremadamente especulativa y casi aventurada hemos decidido no incluir este desarrollo dentro del cuerpo del trabajo.

3 Como recuerda Mercedes de los Reyes Peña (1999), el manuscrito del Códice se encuentra en la Biblioteca Nacional de Madrid (Ms. 14.711). Fue publicado por Léo Rouanet con el título de Colección de Autos, Farsas y Coloquios del siglo XVI en 1901.

4 Citaremos esta obra empleando la edición digital de 2003 hecha por la Biblioteca Virtual Miguel de Cervantes a partir del Ms. 14711 de la Biblioteca Nacional (España), ff. 139r-144r y cotejada con la edición crítica de Miguel Ángel Pérez Priego en Códice de autos viejos. Selección (Madrid, Castalia, 1988, pp.107-139). Hemos preferido esa versión a la de la Colección de Autos, Farsas y Coloquios del siglo XVI, editada por Léo Rouanet en 1901, porque la primera actualiza la ortografía, lo que hace el texto considerablemente más legible. Por ejemplo, la de Rouanet pone en el primer verso "Devotto pueblo xpiano", mientras que la empleada por nosotros consigna: "Devoto pueblo cristiano".

5 Este texto aparece también como La destruicion de Jerusalem, que es como está consignado en la edición que hemos empleado: la de la Nueva Biblioteca de Autores Españoles. Libros de caballerías en su segundo volumen, publicado en 1908 por Bailly-Bailliơere. Para evitar confusiones con sus homónimos teatrales usaremos el título convencional de Historia del noble Vespasiano.

6 Luis Carlos Salazar Quintana (1999) explica que en la Vindicta Salvatoris era el emperador Tiberio quien sufría la lepra y que el nombre de uno de los senescales que aparecen, Velosiano, podría haber derivado en la aparición del emperador Vespasiano en las reformulaciones de la historia.

7 Es necesario apuntar, como recuerda Alberto Ortiz (2007), que el teatro como herramienta de evangelización fue proscrito en 1585 por el Tercer Concilio Mexicano.

8 Esto llevará a Robert Ricard (2017) a afirmar que "[este teatro es] totalmente indio, no por la inspiración, pero sí por la lengua y los actores" (p. 257).

9 Para el caso concreto del Auto de la destrucción de Jerusalén no es un asunto baladí que la reliquia específica se trate del paño de la Verónica. La reliquia en cuestión, además de las propiedades taumatúrgicas que se le atribuyen, trae al texto la pasión de Cristo y refuerza la relación de causalidad entre la culpa de Pilatos/Jerusalén y su castigo por parte de Vespasiano.

10 Es preciso recordar que un desarrollo teatral posterior, como el de la Tragedia del triunfo de los santos de Pedro de Morales, se realizó debido a la llegada de reliquias a territorio novohispano, lo que da cuenta del interés y la vinculación entre teatro y reliquias.

11 En su introducción a Teatro mexicano: Autos, coloquios y entremeses del siglo XVI, Solórzano apunta: "Ajeno al tema de la evangelización los personajes [del Auto de la destrucción de Jerusalén] podían representar, en fácil trasposición, al emperador Carlos $\mathrm{V}$ y a los pueblos que se negaban a someterse totalmente" (1992, p. 14). Como se verá más adelante en el artículo, esta no ha sido la visión principal de la crítica en relación con este tema.

12 Othón Arróniz (1979) apunta que con La conquista de Jerusalén "[t]enemos ante nuestros ojos el primer auto sacramental mexicano" (p. 84). Carmen Corona (1995) ha estudiado las complejidades de esta obra en la que "[e]s muy posible que los franciscanos, apoyados por los tlaxcaltecas, quisieran proyectar por medio de la iconografía escénica una multiplicidad de afirmaciones que no eran realizables en un lenguaje directo" (p. 84). Apunta Corona que estos dos grupos sentían particular gratitud hacia Hernán Cortés, por lo que en el auto decidieron asignarle el único rol análogo al del emperador cristiano. Por otro lado, las ideas milenaristas de esta obra, como la asunción de que la reconquista cristiana de la Ciudad Santa era un requisito del final de los tiempos, han sido estudiadas con asiduidad por Mercedes Serna (2020).

13 El Vespasiano del auto europeo es un monarca grande - naturalmente gentil, pero su conversión es inmediata en cuanto accede al mensaje cristiano-, el cual parece haberse alejado del vicioso emperador de la Historia. Esta remodelación del personaje podría ser ya una anticipación de lo que nosotros consideramos será decisivo en el auto americano: la condición de "caballero de Cristo" y justiciero tanto en lo político como en lo religioso. Los grabados que Cacho Blecua (2016) consigna dan cuenta de que el emperador mesiánico es una construcción que se estuvo gestando en el tiempo: la fusión entre pasado y presente asomaba ya en las versiones editoriales de la antigua leyenda; así, los grabados 
de la curación de Vespasiano que ilustran las ediciones de Lyon (Pierre Boutellier, h. 1488) y de Sevilla (Pedro Brun, 1499) presentan en el dosel del lecho del emperador no el águila romana, sino el águila bicéfala, heráldica del Sacro Imperio desde el Cuatrocientos. Lo que nosotros queremos destacar, en todo caso, es que las connotaciones que acompañan a la construcción del personaje del emperador no serán del todo las mismas en la Península y en América, aunque el proceso analógico parece común.

14 Del total de 680 versos que tiene la edición empleada, el consejo de Archelao se ubica en los versos 271-275.

15 Buena parte del mensaje antisemita viene de la "doble culpabilidad" de Pilatos ("judaizado" para la ocasión). Importante es recordar que más allá del sentimiento antijudío (y sabiendo que en el auto hay también algún que otro "buen judío" debidamente "cristianizado"), la obra castellana se presenta con aires de tragedia a la antigua: un gobernante lleva a la ruina a todo un pueblo. Su dimensión política resulta innegable.

\section{Referencias bibliográficas}

Anónimo. (1901). Aucto de la destruicion de Jerusalén. En L. Rouanet (Ed.), Colección de Autos, Farsas y Coloquios del siglo XVI (502-524), 4 vols. L'Avenç, Librería de M. Murillo.

Anónimo. (1908). La destruicion de Jerusalen. En Nueva Biblioteca de Autores Españoles. Libros de caballerías (vol. 2, 379-401). Bailly-Bailliorere.

Anónimo. (1974). La destrucción de Jerusalén. En F. Horcasitas, El teatro náhuatl. Épocas novohispana y moderna. Primera parte (464-495). Instituto de Investigaciones Históricas, Universidad Nacional Autónoma de México.

Anónimo. (2003). Auto de la destrucción de Jerusalén (Biblioteca Virtual Cervantes, Ed.). Biblioteca Virtual Miguel de Cervantes. http://www.cervantesvirtual.com/nd/ ark:/59851/bmc445m6

Aracil Varón, B. (1999). Del texto literario a la representación popular sobre la conquista: La destrucción de Jerusalén. Anales de Literatura Española, 13, 28-40. https://doi. org/10.14198/ALEUA.1999.13.03

Aracil Varón, B. (2000). Teatro e ideología en el siglo XVI novohispano: la conquista de Jerusalén. En D. Meyrán y A. Ortiz (Eds.), El teatro mexicano visto desde Europa: Actes des 1res Journées Internationales sur le Théâtre Mexicain en France 14, 15, et 16 juin 1993. Alicante: Biblioteca Virtual Miguel de Cervantes. http://www.cervantesvirtual.com/nd/ark:/59851/bmctq5w4

Aracil Varón, B. (2016). La función evangelizadora del teatro breve en la Nueva España del siglo XVl. América sin nombre, 21, 39-48. https://doi.org/10.14198/ AMESN.2016.21.02

Arróniz, O. (1979). Teatro de evangelización en Nueva España. Ciudad de México: Universidad Nacional Autónoma de México.

Cacho Blecua, J. M. (2016). Texto e imagen en la Estoria del noble Vespasiano (Sevilla, 1499): la curación del Emperador. Revista de Poética Medieval, 30, 55-80. https:// doi.org/10.37536/RPM.2016.30.0.50287

Corona, C. (1995). El auto "La conquista de Jerusalén": Hernán Cortés y la transgresión de la figura. En Campbell Y. (Ed.), El escritor y la escena III: estudios en honor de Francisco Ruiz Ramón: actas del III Congreso de la Asociación Internacional de Teatro Español y Novohispano de los Siglos de Oro (9-12 de marzo de 1994, Ciudad Juárez) (79-87). Ciudad Juárez: Universidad Autónoma de Ciudad Juárez. http:// www.cervantesvirtual.com/nd/ark:/59851/bmc4t754

Cortés, H. (1866). Cartas y relaciones de Hernán Cortés al emperador Carlos V. París: Imprenta Central de los Ferro-Carriles A. Chaix y $\mathrm{C}^{a}$.

Faudree, P. (2015). Reading the Requerimiento Performatively: Speech Acts and the Conquest of the New World. Colonial Latin American Review, 24 (4), 456-478. https:// doi.org/10.1080/10609164.2016.1150029 
Flores, E. (2003). La destrucción de Jerusalén: fantasma, violencia y conquista en un libro de cordel del siglo XVI. Revista de Literaturas Populares, l, 67-86. http://rlp.culturaspopulares. org/textos/5/05-Flores.pdf

Garcilaso de la Vega, I. (2009 [1617]). Historia general del Perú. SCG. http://shemer.mslib.huji. ac.il/lib/W/ebooks/001531298.pdf

Hook, D. (2018). Un dato más para la historia de la difusión de la leyenda de la destrucción de Jerusalén. Medievalia, 50, 233-235. https://doi.org/10.19130/medievalia.50.2018.358.

Horcasitas, F. (1974). La destrucción de Jerusalén. En F. Horcasitas, El teatro náhuatl. Épocas novohispana y moderna. Primera parte (461-463). Instituto de Investigaciones Históricas, Universidad Nacional Autónoma de México.

Kamen, H. (2007). Vicisitudes de una potencia mundial, 1500-1700. En R. Carr (Ed.), Historia de España (155-171). Península.

Lida de Malkiel, M. R. (1973). Jerusalén: El tema literario de su cerco y destrucción por los romanos. Universidad de Buenos Aires, Facultad de Filosofía y Letras, Instituto de Filología y Literatura Hispánica.

López de Palacios, J. (2016 [1513]). Texto del requerimiento. https://ciudadseva.com/texto/ requerimiento/

Marín Guzmán, R. (2006). Sociedad, política y protesta popular en la España musulmana. San José: Editorial Universidad de Costa Rica.

Motolinía, T. (2014 [1541]). Historia de los indios de la Nueva España (M. Serna y B. Castany Prado, Eds.). Real Academia Española, Centro para la Edición de los Clásicos Españoles.

Ortiz, A. (2007). Teatro evangelizador en la Nueva España: El primer momento. En Las dos orillas: actas del XV Congreso de la Asociación Internacional de Hispanistas. Monterrey, México, del 19 al 24 de julio de 2004 (359-366). Fondo de Cultura Económica.

Reyes Peña, M. de los. (1999). El Drama sacramental en el "Códice de Autos Viejos". Cuadernos de Historia Moderna, 23, 17-46. https://revistas.ucm.es/index.php/CHMO/article/view/ CHMO9999220017A

Ricard, R. (2017). La conquista espiritual de México: Ensayo sobre el apostolado y los métodos misioneros de las órdenes mendicantes en la Nueva España de 1523-1524 a 1572. Fondo de Cultura Económica.

Salazar Quintana, L. C. (1999). Ideología y transgresión histórica en el teatro doctrinal novohispano: La destrucción de Jerusalén. Revista de Humanidades: Tecnológico de Monterrey, 7, 147-155. https://bivir.uacj.mx/Reserva/Documentos/rva2005106.pdf

Serna, M. (2020). El origen de los indios, la reconquista de Jerusalén y el fin de los tiempos en la Historia de los indios de la Nueva España, de fray Toribio de Benavente, "Motolinía". Hipogrifo. Revista de literatura y cultura del Siglo de Oro, 8 (1), 295-306. https://doi. org/10.13035/H.2020.08.01.21

Solórzano, C. (1992). Teatro mexicano: Autos, coloquios y entremeses del siglo XVI. Consejo Nacional para la Cultura y las Artes.

Weckmann, L. (1994). La herencia medieval de México (2. ${ }^{a}$ ed. revisada). Ciudad de México: El Colegio de México, Fondo de Cultura Económica. 